\title{
Seroprevalence of human herpesvirus 8 infection in children born to HIV-1- infected women in São Paulo, Brazil
}

\author{
D.M. Machado ${ }^{1,2}$, \\ L.M. Sumita ${ }^{1}$, \\ C.S. Pannuti ${ }^{1}$ \\ R.C.M. Succi ${ }^{2}$, \\ M.I. Moraes-Pinto ${ }^{2}$ \\ and V.A.U.F. Souza ${ }^{1}$
}

\author{
'Laboratório de Virologia, Instituto de Medicina Tropical de São Paulo, LIMHC, \\ Departamento de Moléstias Infecciosas e Parasitárias, Faculdade de Medicina, \\ Universidade de São Paulo, São Paulo, SP, Brasil \\ ${ }^{2}$ Centro de Atendimento da Disciplina de Infectologia Pediátrica, \\ Escola Paulista de Medicina, Universidade Federal de São Paulo, São Paulo, \\ SP, Brasil
}

\section{Correspondence \\ D.M. Machado \\ Departamento de Moléstias Infecciosas \\ e Parasitárias, FM, USP Av. Dr. Enéas C. Aguiar, 470 05403-000 São Paulo, SP Brasil \\ Fax: +55-11-3063-2659}

Research supported by Fundo de Auxílio aos Docentes e Alunos (FADA-UNIFESP).

Publication supported by FAPESP.

Received September 22, 2003 Accepted October 13, 2004

\begin{abstract}
Human herpesvirus-8 (HHV-8) appears to be transmitted mainly by sexual contact. However, several studies suggest that in developing countries the infection may be acquired early in life by routes other than sexual transmission. The present study estimated the seroprevalence of HHV-8 in Brazilian children born to HIV-1-infected mothers. The serum samples were collected in a cross-sectional cohort study from 99 children born to HIV-infected mothers (median age 3.27 years; range 1.5-13.8 years) attending the outpatient clinic of the Federal University of São Paulo. IgG antibodies to HHV-8 latencyassociated nuclear antigen and lytic phase antigens were detected by immunofluorescence assays. The samples tested were collected from children aged 12 months or older to exclude the possibility of crossplacental antibody transport. The total prevalence of anti-lytic antibodies in this population $(5 / 99 ; 5 \%)$ reveals that HHV-8 infection can occur during childhood. Children aged 1.5 to 2 years had a seroprevalence of $2 \%(1 / 50)$ and children aged 3.25 to 13.8 years had a seroprevalence of $8 \%$ (4/49). This difference was not statistically significant, probably because of the small size of the sample, but it suggests that HHV-8 infection occurs more commonly late in infancy. Further prospective studies are necessary to evaluate the timing and risk factors for primary HHV-8 infection in the pediatric population.
\end{abstract}

Human herpesvirus-8 (HHV-8), recently discovered by Chang et al. (1), is etiologically associated with all forms of Kaposi's sarcoma (KS; 2$)$ and other rare malignancies (3). The routes of HHV-8 transmission differ according to geographic factors and behavioral patterns. In industrialized western countries, HHV-8 is transmitted mainly by sexual contact (4) and its prevalence is low in chil-
Key words - HHV-8

- Seroprevalence

- AIDS

- Children

- LANA-IFA

- Lytic-IFA dren (5). However, several studies have suggested that in developing countries the infection may be acquired early in life through routes other than sexual transmission, involving body fluids like nasal secretions and saliva (6). In endemic populations, HHV-8 transmission can occur from mother to child and between sibling, by close interpersonal contact (7-9). The prevalence of HHV-8 anti- 
bodies ranges from 30-60\% in adult African populations with high rates of KS (10) and also in children without KS $(11,12)$.

In Brazil, seroprevalence rates of 4.6 and $7.4 \%$ were reported among blood donors in the cities of Vitória and São Paulo, respectively $(13,14)$. Studies conducted in the Northern region of the country showed an overall $16.3 \%$ prevalence of HHV-8 in urban communities (15) and a high prevalence among Brazilian Amerindians (53\%), even among children less than 10 years of age (41\%) (16). Souza et al. (17) studied healthy children and adults from different cities in São Paulo State and detected a 1.0 to $4.1 \%$ prevalence of HHV-8 antibodies by latencyassociated nuclear antigen (LANA-IFA) or lytic phase antigens-immunofluorescence assays (Lytic-IFA). A high prevalence of HHV-8 antibodies has been observed in AIDS patients (39.2\%) and an $8.0 \%$ frequency of anti-lytic antibodies was recently found among HIV-1-infected women from São Paulo (18). Antiretroviral treatment has dramatically reduced morbidity and mortality in both adults and children infected with HIV. Children born to HIV-infected mothers have survived longer, being exposed to several other viral agents, including HHV-8. Previous studies have reported the occurrence of HHV-8 transmission within families, from mothers and other relatives to children via the horizontal route, as well as significant correlations between the HHV-8 serostatus of mothers and children (8).

In view of these considerations, the objective of the present study was to estimate the seroprevalence of HHV-8 among Brazilian children born to HIV-infected mothers. The study was conducted according to the ethical guidelines set by the Brazilian Health Ministry for research on human beings, and was approved by the Research Ethics Committee of the Federal University of São Paulo.

The serum samples included in the study were collected from a cross-sectional cohort of 99 children (median age, 3.27 years; range
1.5-13.8 years) born to HIV-infected mothers attending the outpatient clinic of the Federal University of São Paulo.

Of these, 49 were HIV-infected children ( 25 females) and 50 ( 24 females) were vertically exposed but uninfected. The median age was lower for the uninfected (1.99 years; range 1.5-2 years) than for the HIV-infected children (5.36 years; range 3.75-13.8 years).

The samples tested were obtained from children aged 12 months or older to exclude the possibility of cross-placental antibody transport.

Antibodies to HHV-8, LANA-IFA and Lytic-IFA were detected by IFA. IFA were performed using the BCBL-1 cell line as described previously (17). The viral lytic cycle was induced by incubating BCBL-1 cells with $20 \mathrm{ng} / \mathrm{ml}$ 12-o-tetradecanoylphorbol-13-acetate (TPA) for $96 \mathrm{~h}$. Punctuate nuclear staining in untreated BCBL-1 cells was considered to indicate positivity for antibodies to LANA. Entire cell fluorescence in about $20 \%$ of the TPA-treated cells was considered to indicate positivity for antibodies to the lytic phase antigens.

Five children (4 HIV-infected and 1 uninfected) were anti-lytic antibody positive. According to the Pediatric Classification for HIV infection in children (Centers for Disease Control, 1994), 48 of the 49 children from the infected group already exhibited HIV-related symptoms (A, B or C) and 1 child was not symptomatic. No HHV-8- seropositive children showed clinical evidence of KS.

The total prevalence of HHV-8 antibodies in the population studied $(5 / 99,5 \%)$ reveals that HHV-8 infection can occur during childhood. However, in this study we could not ascertain exactly when the children became infected, since the infants were not tested at different intervals after birth. HHV-8 infection is common in HIV-positive patients, being significantly higher in HIV-positive homosexual men as compared to HIV-infected patients showing other behavioral risk 
factors. In the present study, the prevalence of HHV-8 infection in HIV-infected mothers was not evaluated, and although in previous studies undertaken in São Paulo State, the prevalence rate of HHV-8 antibodies in women ranged from 7.9 to $18.8 \%(17,18)$, there are no data that allow us to compare these groups. The higher prevalence of HHV8 infection in HIV-infected patients than that seen in healthy Brazilian adults, taken together with the demonstration of HHV-8 DNA in cervical scrapes from HIV-infected women (19), suggest that, theoretically, children born to HIV-infected mothers could be at risk of acquiring HHV-8 infection. In the current study, the prevalence rate of HHV-8 antibodies in children born to HIV-positive mothers varied according to age group. Children aged 1.5 to 2 years had a prevalence rate of $2 \%(1 / 50)$ and children aged 3.5 to 13.8 years had a prevalence rate of $8.2 \%$ (4/49). This difference was not statistically significant, probably because of the small size of the sample.

In a previous study conducted on healthy children from the general population of São Paulo State, not vertically exposed to HIV, the prevalence rate of HHV-8 antibodies found in 12- to 23-month-old children (3/ $177 ; 1.7 \%$ ) was similar to that found in $2-$ to 10 -year-old children $(1 / 98 ; 1 \%)$. Although we cannot ascertain that the populations participating in both studies were comparable, the results make us wonder if the population in the present study was exposed to HHV-8 earlier in life.

The Lytic-IFA showed a greater sensitivity than the LANA-IFA in detecting HHV-8 antibodies. This is not unexpected, since even in KS patients, the anti-LANA-IFA shows a lower sensitivity compared to the Lytic-IFA (20). There are many discrepancies among the studies regarding the results obtained by the different methods used to detect HHV-8 antibodies, and the lack of a "gold standard" hampers the interpretation of seroepidemiological studies. Further prospective studies are necessary to evaluate the timing and risk factors for primary HHV-8 infection in the pediatric population.

\section{References}

1. Chang Y, Cesarman E, Pessin MS, Lee F, Culpepper J, Knowles DM \& Moore PS (1994). Identification of herpesvirus-like DNA sequences in AIDS-associated Kaposi's sarcoma. Science, 266: 18651869.

2. Shulz TF (1998). Kaposi's sarcoma-associated herpesvirus (human herpesvirus 8). Journal of General Virology, 79: 1573-1591.

3. Inagi R, Kosuge H, Nishimoto S, Yoshikawa K \& Yamanishi K (1996). Kaposi's sarcoma-associated herpesvirus (KSHV) sequences in premalignant and malignant skin tumors. Archives of Virology, 141: 2217-2223.

4. Martin JN, Ganem DE, Osmond DH, Page-Shafer KA, Macrae D \& Kedes DH (1998). Sexual transmission and the natural history of human herpesvirus 8 infection. New England Journal of Medicine, 338: $948-954$

5. Blauvelt A, Sei S, Cook PM, Shulz TF \& Jeang KT (1997). Human herpesvirus 8 infection occurs following adolescence in the United States. Journal of Infectious Diseases, 176: 771-774.

6. Blackbourn DJ, Lennete ET, Ambroziak J, Mourich DV \& Levy JA (1998). Human herpesvirus 8 detection in nasal secretions and saliva. Journal of Infectious Diseases, 177: 213-216.

7. Lyall EG, Patton GS, Sheldon J, Stainsby C, Mullen J, O'Shea S, Smith NA, De Ruiter A, McClure MO \& Schulz TF (1999). Evidence for horizontal and not vertical transmission of human herpesvirus 8 in children born to human immunodeficiency virus-infected mothers. Pediatric Infectious Disease Journal, 18: 795-799.

8. Plancoulaine $S$, Abel L, van Beveren M, Tregouet DA, Joubert M, Tortevoye P, de The G \& Gessain A (2000). Human herpesvirus 8 transmission from mother to child and between siblings in an endemic population. Lancet, 356: 1062-1065.

9. Andreoni M, el-Sawaf G, Rezza G, Ensoli B, Nicastri E, Ventura L, Ercoli L, Sarmati L \& Rocchi G (1999). High seroprevalence of antibodies to human herpesvirus-8 in Egyptian children: evidence of nonsexual transmission. Journal of the National Cancer Institute, 91: 465-469.

10. Olsen SJ, Chang Y, Moore PS, Biggar RJ \& Melbye M (1998). Increasing Kaposi's sarcoma-associated herpesvirus seroprevalence with age in a highly Kaposi's sarcoma endemic region, Zambia in 1985. AIDS, 12: 1921-1925.

11. Sitas F, Carrara H, Beral V et al. (1999). Antibodies against human herpesvirus 8 in black South African patients with cancer. New England Journal of Medicine, 340: 1863-1871.

12. Mayama S, Cuevas L, Sheldon J, Omar OH, Smith DH, Okong $P$, Silvel B, Hart CA \& Shulz TF (1998). Prevalence and transmission of Kaposi's sarcoma-associated herpesvirus (human herpesvirus 8) in 
Ugandan children and adolescents. International Journal of Cancer, 77: 817-820.

13. Caterino-de-Araujo A, Calabrò ML, Santos-Fortuna E, Suleiman J \& Chieco-Bianchi L (1999). Searching for human herpesvirus 8 antibodies in serum samples from patients infected with human immunodeficiency virus type 1 and blood donors from Sao Paulo, Brazil. Journal of Infectious Diseases, 179: 1591-1592.

14. Zago A, Bourboulia D, Viana MC, Collandre H, Dietze R, Boshoff C \& Keller R (2000). Seroprevalence of human herpesvirus 8 and its association with Kaposi sarcoma in Brazil. Sexually Transmitted Diseases, 27: 468-472.

15. Freitas RB, Freitas MR \& Linhares AC (2002). Prevalence of human herpesvirus 8 antibodies in the population of Belém, Pará, Brazil. Revista do Instituto de Medicina Tropical de São Paulo, 44: 309-313.

16. Biggar RJ, Whitby D, Marshall V, Linhares AC \& Black F (2000). Human herpesvirus 8 in Brazilian Amerindians: a hyperendemic population with a new subtype. Journal of Infectious Diseases, 181: 1562-1568.

17. Souza VAUF, Sumita LM, Freire W, Sato HK, Grandi JL, Pierroti LC,
Nascimento MCP \& Pannuti CS (2003). Prevalence of antibodies to human herpesvirus-8 (HHV-8) in populations with and without risk for HHV-8 infection in São Paulo State, Brazil. Brazilian Journal of Medical and Biological Research, 37: 123-127.

18. Caterino-de-Araújo A, Santos-Fortuna E, Carbone PH, Cibella SE \& Moreira AA (2003). Human herpesvirus-8 (HHV-8) antibodies in women from São Paulo, Brazil. Association with behavioral factors and Kaposi's sarcoma. Brazilian Journal of Infectious Diseases, 7: 395-401.

19. Sumita LM, Levi JE, Fink MCDS, Pannuti CS, Segurado AAC, Linhares IM, Matsubara R \& Souza VAUF (1998). Detection of human herpesvirus 8 (HHV-8) DNA in cervical scrapes from HIVinfected patients. Virus Reviews and Research, 3 (Suppl 1): 116 (Abstract).

20. Pierrotti LC, Masami SL, Santos FW, Caiaffa Filho HH \& Souza VAUF (2000). Detection of human herpesvirus 8 DNA and antibodies to latent nuclear and lytic-phase antigens in serial samples from AIDS patients with Kaposi's sarcoma. Journal of Clinical Virology, 16: 247-251. 